\title{
Genomic organization of duplicated major histocompatibility complex class I regions in Atlantic salmon (Salmo salar)
} Morten F Lukacs ${ }^{1}$, Håvard Harstad ${ }^{1}$, Unni Grimholt ${ }^{1}$, Marianne BeetzSargent ${ }^{2}$, Glenn A Cooper ${ }^{2}$, Linda Reid ${ }^{2}$, Hege G Bakke ${ }^{1}$, Ruth B Phillips ${ }^{3}$, Kristina M Miller ${ }^{4}$, William S Davidson ${ }^{5}$ and Ben F Koop*2

Address: ${ }^{1}$ Department of Basic Science and Aquatic Medicine, Norwegian School of Veterinary Science, Oslo, Norway, ${ }^{2}$ Department of Biology, University of Victoria, Victoria BC V8W 2Y2, Canada, ${ }^{3}$ Biological Sciences, Washington State University Vancouver, Vancouver, Washington, USA, ${ }^{4}$ Molecular Genetics, Pacific Biological Station, Fisheries and Oceans Canada, Nanaimo, BC, Canada and ${ }^{5}$ Department of Molecular Biology \& Biochemistry, Simon Fraser University, Burnaby, BC, Canada

Email: Morten F Lukacs - morten.lukacs@veths.no; Håvard Harstad - havard.harstad@veths.no; Unni Grimholt - unni.grimholt@veths.no; Marianne Beetz-Sargent - marianbs@uvic.ca; Glenn A Cooper - gac@uvic.ca; Linda Reid - linda.l.reid@gmail.com;

Hege G Bakke - hege.bakke@veths.no; Ruth B Phillips - phllipsr@vancouver.wsu.edu; Kristina M Miller - millerk@pac.dfo-mpo.gc.ca; William S Davidson - wdavidso@sfu.ca; Ben F Koop* - bkoop@uvic.ca

* Corresponding author

Published: 25 July 2007

BMC Genomics 2007, 8:25I doi:10.1|86/|47|-2164-8-25|
Received: 27 February 2007

Accepted: 25 July 2007

This article is available from: http://www.biomedcentral.com/l47|-2164/8/25 I

(C) 2007 Lukacs et al; licensee BioMed Central Ltd.

This is an Open Access article distributed under the terms of the Creative Commons Attribution License (http://creativecommons.org/licenses/by/2.0), which permits unrestricted use, distribution, and reproduction in any medium, provided the original work is properly cited.

\begin{abstract}
Background: We have previously identified associations between major histocompatibility complex (MHC) class I and resistance towards bacterial and viral pathogens in Atlantic salmon. To evaluate if only $\mathrm{MHC}$ or also closely linked genes contributed to the observed resistance we ventured into sequencing of the duplicated MHC class I regions of Atlantic salmon.

Results: Nine BACs covering more than $500 \mathrm{~kb}$ of the two duplicated MHC class I regions of Atlantic salmon were sequenced and the gene organizations characterized. Both regions contained the proteasome components PSMB8, PSMB9, PSMB9-like and PSMBIO in addition to the transporter for antigen processing TAP2, as well as genes for KIFCI, ZBTB22, DAXX, TAPBP, BRD2, COLIIA2, RXRB and SLC39A7. The IA region contained the recently reported MHC class I Sasa-ULA locus residing approximately $50 \mathrm{~kb}$ upstream of the major Sasa-UBA locus. The duplicated class IB region contained an MHC class I locus resembling the rainbow trout UCA locus, but although transcribed it was a pseudogene. No other MHC class I-like genes were detected in the two duplicated regions. Two allelic BACs spanning the UBA locus had $99.2 \%$ identity over I $25 \mathrm{~kb}$, while the IA region showed $82.5 \%$ identity over I $36 \mathrm{~kb}$ to the IB region. The Atlantic salmon IB region had an insert of $220 \mathrm{~kb}$ in comparison to the IA region containing three chitin synthase genes.

Conclusion: We have characterized the gene organization of more than $500 \mathrm{~kb}$ of the two duplicated MHC class I regions in Atlantic salmon. Although Atlantic salmon and rainbow trout are closely related, the gene organization of their IB region has undergone extensive gene rearrangements. The Atlantic salmon has only one class I UCA pseudogene in the IB region while trout contains the four MHC UCA, UDA, UEA and UFA class I loci. The large differences in gene content and most likely function of the salmon and trout class IB region clearly argues that sequencing of salmon will not necessarily provide information relevant for trout and vice versa.
\end{abstract}




\section{Background}

Major histocompatibility complex (MHC) class I and class II molecules are vital parts of the cellular immune system presenting self and/or foreign peptides to CD8 positive and CD4 positive T cells. Both classes of genes reside in a $4 \mathrm{Mb}$ gene dense region on human chromosome 6 shared with many other immune genes [1].

Atlantic salmon and rainbow trout genomes encode one major MHC class I locus designated UBA in addition to the major $\mathrm{MHC}$ class II alpha and beta genes designated $D A A$ and $D A B$ respectively [2-4]. For $U B A$, the main polymorphism resides in the alpha 1 and alpha 2 domains with up to $60 \%$ sequence divergence between these antigen binding domains. Added variability for $U B A$ is produced by shuffling of exon 2 onto different exon 3 and downstream regions through recombination occurring in intron 2 [4]. Additional class I loci and lineages have been described in both Atlantic salmon as well as in rainbow trout. The majority of reported salmonid MHC class I molecules are classified into a U-lineage consisting of both UBA as well as non-classical MHC molecules [5,6]. Two other described MHC class I-like lineages are ZE described by Miller et al. [5] and L described by Dijkstra et al. [7].

In all teleosts studied so far including salmonids the MHC class I and class II regions are unlinked [3,8]. Sequence data on the MHC class I region is available from zebrafish [9], fugu [10], medaka $[11,12]$ and rainbow trout [6]. A general feature of these four MHC class I regions is a core region containing genes for the proteasome components (PSMBs) and the transporter for antigen processing (TAP2) being flanked by various numbers of MHC class I loci in addition to many other genes also residing in the human MHC region located on chromosome 6. Data from medaka and zebrafish indicate that other fish orthologs of the mammalian MHC-encoded genes are dispersed on several different chromosomes [13-16], similar to the paralogue MHC regions described on human chromosomes 1, 9 and 19 [17]. Salmonids are seen as partially tetraploid with a unique whole genome duplication occurring between 25 and 125 million years ago (mya) with remnants of tetraploidy visible also today [18-20]. Shiina et al. [6] sequenced two duplicated core MHC regions of rainbow trout. Based on sequence divergence they estimated the duplication event to have taken place approx. 60 mya, in agreement with the salmonid whole genome duplication theory. The classical or IA region contained the major expressed classical MHC class I UBA locus while the duplicated region denoted IB contained the four Onmy-UCA, -UDA, -UEA and -UFA class I loci. Based on expression and polymorphism data, Onmy-UCA, -UDA and -UEA were defined as non-classical loci and -
UFA as a pseudogene due to an incapacitating mutation in exon 3 [6].

Data is rapidly emerging on associations between MHC and resistance to salmonid pathogens. In Atlantic salmon, UBA genotypes have been found to provide resistance towards Aeromonas salmonicida and Infectious Salmon Anaemia Virus [21,22]. Class IB, but not class IA was found associated with susceptibility towards infectious hematopoietic necrosis virus (IHNV) in Atlantic salmon and towards infectious pancreatic necrosis virus (IPNV) in rainbow trout $[23,24]$.

Both trout and salmon are main aquaculture species and understanding their immune systems will improve our understanding of how these regions influence disease resistance and thus improve our breeding schemes for the trait. Atlantic salmon and rainbow trout are estimated to have split approx. 20 mya [25]. As Atlantic salmon is a major aquaculture species and displays some differences in response to pathogens when compared to rainbow trout [26], we ventured into sequencing of the two duplicated MHC class I regions of Atlantic salmon. Here we describe the gene organization of these two MHC class I regions comprising approx. $500 \mathrm{~kb}$ each and compare our results to data from other teleosts.

\section{Results and discussion}

The aim of this study was to characterize the gene organization and identify new genes potentially contributing to disease resistance in the two MHC class I regions of Atlantic salmon.

\section{Characterization and sequencing of $B A C$ clones}

Sasa-UBA and TAP2 probes hybridized to 74 BAC clones, where 18 clones were positive for both probes. The 74 $\mathrm{BAC}$ clones were ordered into three contigs using restriction fragment analysis together with GRASP HindIII fingerprint information [27].

The two contigs that were positive for UBA, TAP2, PSMB9 and PSMB8 by southern hybridization, were tested for presence of a polymorphic dinucleotide repeat located in the 3'UTR of the UBA locus [3]. Only BAC clones from one of the two contigs gave PCR-products, thus this contig was defined as the IA region, and the other contig remained a candidate for the duplicated $\mathrm{IB}$ region. The $\mathrm{BAC}$ clones in the third contig hybridized to the UBA probe as well as a mixed UBA exon 2 probe. These clones also tested positive for a U-lineage ULA locus that has previously been found closely linked to UBA [5].

Three BACs were sequenced from the IA region. The BAC clones 92I04 and 714P22 indicated allelic variants based on variation in the UBA 3'UTR marker (data not shown) 
with $523 \mathrm{M} 19$ as a continuation of $714 \mathrm{P} 22$. From the duplicated IB region we chose 8I14, 424M17, 15L20 and $189 \mathrm{M} 18$ for sequencing. 30C23 was chosen as a candidate from the third contig and was extended $5 \mathrm{~kb}$ with the sequence of 868001 . The selected BAC clones were subcloned, sequenced, and assembled into continuous sequences. The Atlantic salmon IA region consisted of the BAC clones 30C23, 868O01, 92I04, 714P22 and 523M19 covering $502869 \mathrm{bp}$, while the IB region consisted of $8 \mathrm{I} 14,424 \mathrm{M} 17,15 \mathrm{~L} 20$ and 189M18 totaling $522617 \mathrm{bp}$.

\section{Gene organization of the Atlantic salmon MHC class I regions}

We have adopted the nomenclature described by Shiina et al. [6] with IA covering the UBA locus region and IB for the duplicated region. Thus the genes identified in the regions will be named accordingly; the IA proteasome subunits are given an extension of a (PSMB9a) and the IB genes have an extension of $b$ (PSMB9b). The previous symbol ABCB3 has been withdrawn for the transporter for antigen processing 2, so we have used the current symbol TAP2 [28].

The gene organization of the IA and IB MHC regions is shown in Fig. 1. A core region was identified in both regions which included $M H C$ class I genes, together with the proteasome subunits genes PSMB8 (LMP7), PSMB10 (MECL-1), PSMB9-like (LMP2- $)$, PSMB9 (LMP2) and TAP2. The gene order and orientation of the Atlantic salmon PSMBs and TAP2 was very similar to that found in rainbow trout and other teleost (Fig. 2). For the IA region, the main difference between Atlantic salmon and rainbow trout is that the rainbow trout PSMB8a gene is a pseudogene.

The IA region contained the major MHC class I Sasa-UBA locus and the recently reported Sasa-ULA locus residing approximately $50 \mathrm{~kb}$ upstream. The duplicated class IB region contained an $\mathrm{MHC}$ class I locus resembling the rainbow trout UCA locus, but although transcribed it was a pseudogene. No other MHC class I-like genes were detected in the two duplicated regions.

Outside the core region we found 12 Atlantic salmon orthologs of genes residing in the extended human MHC class II region. Alternative nomenclature for these genes is described in Table 1 . The following genes were found in both the IA and IB regions; KIFC1, ZBTB22, DAXX, TAPBP, BRD2, COL11A2, RXRB and SLC39A7. Three orthologs found in the IA region only were RING1, RPS18 and VPS52. For other teleosts, the gene organization of the extended MHC class I region is partly known for zebrafish $[9,16]$, fugu $[10,15]$ and medaka $[11,12]$. The TAPBP, DAXX, ZBTB22 and KIFC1 genes are conserved in the same order in both fish and human (Fig. 2). As described in medaka we also found a gene for ZNF384 in the IA region, which is located on Chromosome 12 in human.

HSD17B8, which resides in between SLC39A7 and RING1 in the extended human class II region, was found in the IB region only and showed more than $81 \%$ identity towards counterparts in tilapia [Genbank:AAV74184], zebrafish [Genbank:CAK04961] and medaka [Genbank:BAB83840]. HSD17B8 has thus been deleted from the Atlantic salmon IA region as it is also present in other fish MHC class I regions (Fig. 2).

Three orthologs of genes located in the human class I region were identified in the IA region; TCF19, TUBB and FLOT1. Atlantic salmon tubulin is highly conserved and showed more than 94\% identity towards mammalian counterparts. Another highly conserved gene is RPS18, which showed $98 \%$ identity towards mammalian sequences.

A gene that was predicted by DIGIT in the IA region had one EST match [Genbank:DW569240], but no homology to annotated proteins and is thus denoted unknown in Fig. 1. However, some sequence identity was found towards a protein in zebrafish located on chromosome 19 [Genbank:XP 001344849] as well as to a tetraodon nigroviridis protein [Genbank:CAF97811], which could indicate a molecule unique to teleosts.

In addition to the genes described above we identified genes for PVRL2, RT, VSHV-induced gene and a novel gene similar to a non-vertebrate chitin synthase protein that are not MHC linked in humans. The human PVRL2 is located on chromosome 19 (19q13.2-q13.4). A homologue of this gene is also found on zebrafish chromosome 19 [Genbank: XP 689425]. A $220 \mathrm{~kb}$ insertion was found in the IB region in between the RXRB and SLC39A7 genes containing three copies of a chitin synthase gene approx. $45 \mathrm{~kb}$ apart (Figs. 1 and 3). Chitin synthase is involved in the synthesis of chitin, which is a main structural component of the fungal cell wall. A similar protein has also been identified in zebrafish [Genbank:CAK04859]. No chitin synthase genes were present in the IA region nor are chitin synthase genes found in any other teleost MHC regions suggestive of a single insertion of this gene in the IB region with two subsequent duplications (Fig. 2).

Most genes in both regions are supported by matching cDNAs apart from TCF19 and COL11A2 where no match has been found so far (Table 1). Other open reading frames were also identified, but were associated with transposon related repetitive elements. 


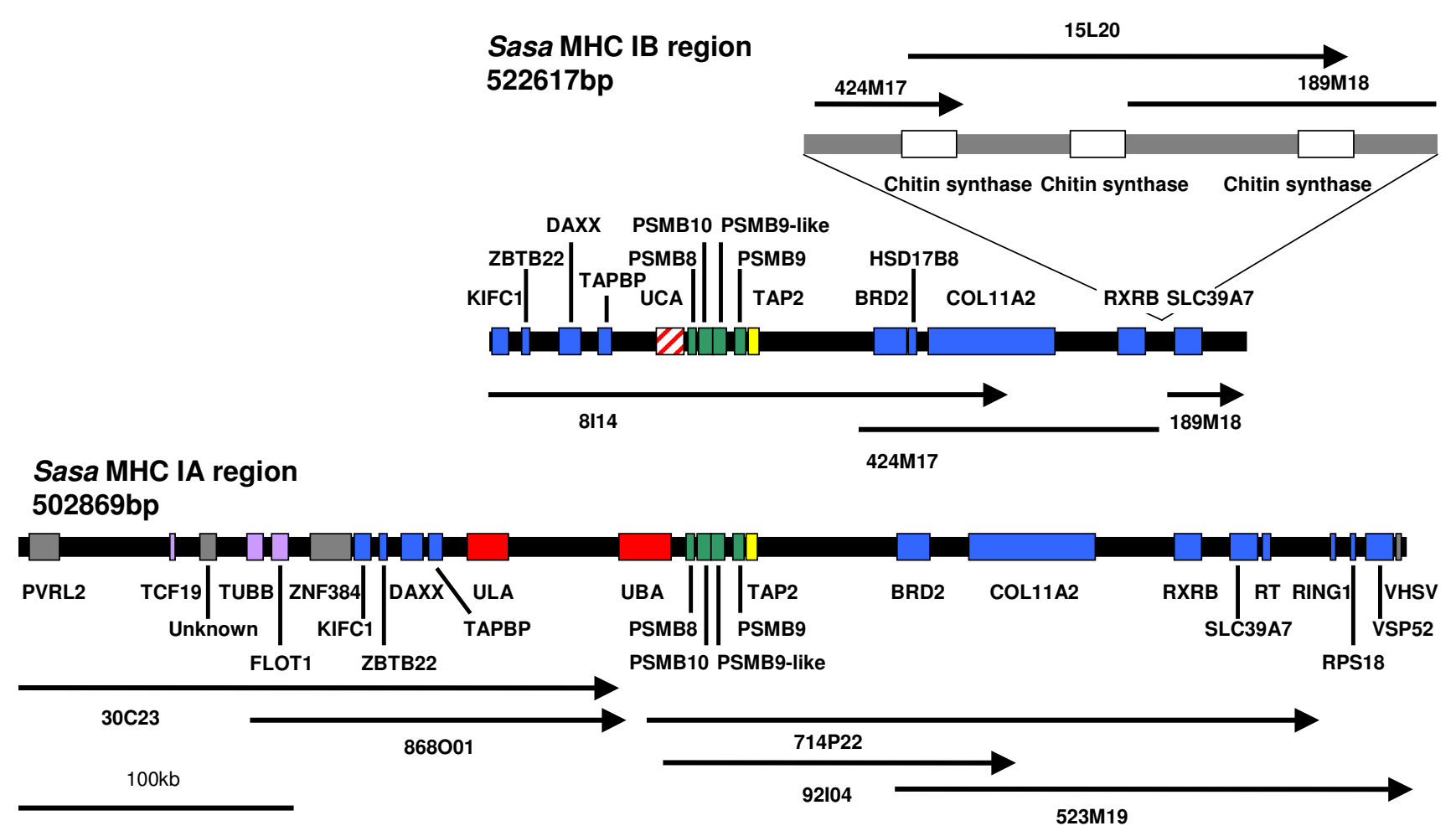

Figure I

Gene organization of Atlantic salmon MHC IA and IB regions. Upper panel is the IB region represented by the BACs $8 I I 4,424 \mathrm{MI}$, I5L20 and I89MI8. Lower panel is the IA region represented by the BACs 30C23, 86800I, 92I04, 7I4P22 and $523 \mathrm{M}$ 19. Locus designation is based on sequence identity to matching ESTs and human nomenclature is used. The regions are drawn to scale.

\section{Comparison of the IA and IB regions}

The two allelic BACs 92I04 and 714P22 had an overall sequences identity of $99.2 \%$ over $124574 \mathrm{bp}$, with similar exon intron organization for all genes. The major differences between the two allelic regions resided in the UBA $\alpha 2$ and $\alpha 3$ exons and in differences in number of repeats (data not shown). Dotplot analysis of 714P22 or 92104 against themselves showed no extended regions of local similarity, with the exception of the TAP2 region which showed similarity due to a duplicated TAP2 exon 11 (data not shown).

A dot plot analysis of more than $500 \mathrm{~kb}$ of the IA and IB regions showed four regions with high sequence similarity consisting of subregion one containing genes for KIFC1 to TAPBP, subregion two ranging from PSMB8 to TAP2, subregion three covering BRD2 to RXRB and subregion four containing SLC39A7 (Fig. 3). The conserved regions in IA and IB have $82.5 \%$ identity over $136104 \mathrm{bp}$. In total, repeats constituted approximately $24 \%$ of the sequence in both regions, and $17 \%$ of the repeats were fish-specific DNA elements.

\section{MHC Class I genes}

\section{Sasa-UBA}

The promoter, leader and $\alpha 1$ exons of Sasa-UBA were identified in 30C23/868O01, while the remaining exons of Sasa-UBA were found in 92I04 and 714P22. The leader and $\alpha 1$ exons found in $30 \mathrm{C} 23 / 868001$ were identical to the PCR amplified $U B A^{*} 0201$ allele [Genbank:AF504023] as well as to the leader and $\alpha 1$ exons of another salmon full-length cDNA [Genbank:DY698957]. Together with the $\alpha 2$ and $\alpha 3$ exons of 92I04 they collectively provide a bona fida $U B A^{*} 0201$ allele. The UBA $\alpha 2$ exon and downstream sequences of the two allelic BACs 92I04 and $714 \mathrm{P} 22$ have complete sequence identity to the Sasa$U B A^{*} 0201 /{ }^{*} 0301$ and Sasa-UBA*0601 alleles respectively. $U B A^{*} 0201$ and $U B A^{*} 0301$ are prime examples of the recombination shown to occur within intron 2 of salmonid UBA alleles [4] showing complete sequence identity in the $\alpha 2$ and downstream regions, but highly divergent $\alpha 1$ exons. The predicted amino acid sequences of UBA, ULA and the two open reading frames of UCA $\psi$ were aligned for comparison of the MHC class I genes encoded in the two regions (Fig. 4). 
Human ( 4Mb)
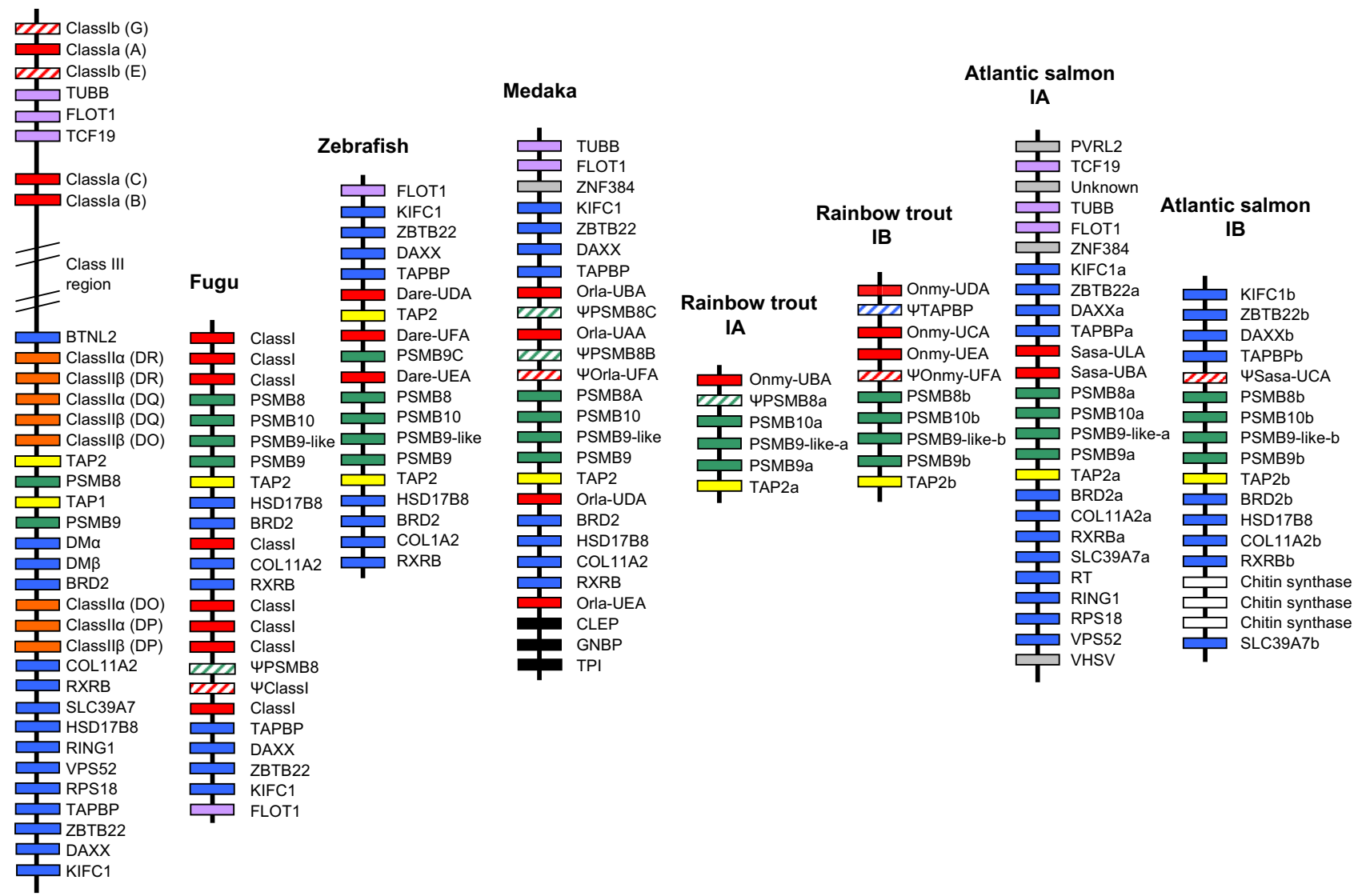

Figure 2

Comparison of the human, Atlantic salmon, rainbow trout, medaka, zebrafish and fugu MHC class I. Color code: red is MHC class I genes, orange is MHC class II genes, yellow is TAP genes, green is proteasome genes, blue is human extended MHC class II region genes, purple is human class I region genes, grey is non-human class I region genes, black is genes unique to the medaka HNI strain [12]. Pseudogenes are striped. Human class III region genes are not shown. References are: zebrafish $[9,16]$, fugu $[10]$, medaka $[11,12]$, rainbow trout $[6]$ and human $[1]$.

Analysis of the promoter sequence of $U B A^{*} 0201$ in $30 \mathrm{C} 23 / 868 \mathrm{O} 01$ showed high similarity to a rainbow trout $U B A^{*} 1501$ promoter [29], both containing similar regulatory elements typical for MHC class I promoters such as an interferon stimulated response element (ISRE), W/S-box and enhancer B (enhB) (Fig. 5). The $U B A^{*} 0201$ promoter contains a potential site $\alpha$ element according to the core sequence (TGACGC) [30] while a sequence more resembling an X2-box has been found in rainbow trout (TGAGGCA). Both the site $\alpha$ and the homologous X2-box found in mammalian MHC class I and MHC class II promoters respectively, are involved in regulation of transcription and bind ATF/CREB family transcription factors [31]. A potential TATA-box was also identified in the promoter sequence of $U B A^{*} 0201$ [32]. A salmon $U B A^{*} 0301$ promoter published by Jorgensen et al. [33] had lower sequence identity to the $U B A^{*} 0201$ promoter, but both promoters are supported by complete identity to 5'UTR cDNA sequences of bona fida $U B A$ alleles suggesting that Atlantic salmon $U B A$ alleles have different promoters. The functional consequences of these differences are being investigated.

The 30C23/868001 and 92I04 BACs jointly have an intron sequence of $7 \mathrm{~kb}$ while in rainbow trout, the intron between the UBA $\alpha 1$ and $\alpha 2$ exons is $18 \mathrm{~kb}$ [6] suggesting we lack approximately $11 \mathrm{~kb}$ to have a continuous genomic sequence of the entire UBA region. PCR and cloning of the gap was performed multiple times, but despite successful PCR amplification no fragments covering the gap have been cloned suggestive of an unclonable region. The amplified products support an intron sequence of approx. $18 \mathrm{~kb}$. Unfortunately no mRNA or cDNA is available from the BAC library fish, preventing 
Table I: EST match to genes in the Atlantic salmon MHC IA and IB regions

\begin{tabular}{|c|c|c|c|c|}
\hline GENE & Abbreviation & Alias & EST/cDNA match IA & EST/cDNA match IB \\
\hline Poliovirus receptor like2 & PVRL2 & & CA342790 & n.i. \\
\hline Transcription factor 19 & TCFI9 & $\mathrm{SCl}$ & $?$ & n.i. \\
\hline UNKNOWN & $?$ & & DW569240 & n.i. \\
\hline Tubulin & TUBB & OK/SW-cl.56 & DW589685 & n.i. \\
\hline Flotillin & FLOTI & & DY703577 & n.i. \\
\hline Zinc finger protein 384 & ZNF384 & $\mathrm{ClZ}$ & CB506768 & n.i. \\
\hline Kinesin family member $\mathrm{Cl}$ & $\mathrm{KIFCI}$ & KNSL2/HSET & DW541824 & $\mathrm{BX} 313539$ \\
\hline Zinc finger and BTB domain & ZBTB22 & ZNF297/BINGI & $B \times 911712$ & $B \times 911712$ \\
\hline Death-associated protein 6 & DAXX & & DY736372 & GRASP cluster 76574 \\
\hline Tapasin & TAPBP & & DY735080 & DW580568 \\
\hline MHC class I & ULA & & DY699730 & n.i. \\
\hline MHC class I & UCA & & n.i. & DW563256 \\
\hline MHC class I & UBA & & $U B A * 0201 / * 0601$ & n.i. \\
\hline Proteasome subunit, beta type, 8 & PSMB8 & LMP7 & DY733578 & AFI84938 \\
\hline Proteasome subunit, beta type, 10 & PSMBIO & MECLI & DY740375 & DY734I68 \\
\hline Proteasome subunit, beta type, 9-like & PSMB9-like & LMP2-delta & DW574810 & CN442539 \\
\hline Proteasome subunit, beta type, 9 & PSMB9 & LMP2 & AFI84935 & AFI84934 \\
\hline Transporter 2, ATP-binding cassette, sub-family B & TAP2 & $A B C B 3$ & DW540744 & Z83328 \\
\hline Bromodomain containing 2 & BRD2 & RING3 & CA349460 & CA349460 \\
\hline Hydroxysteroid (17-beta) dehydrogenase 8 & HSDI7B8 & KE6, FABGL & n.i. & CK880913 \\
\hline Collagen, type XI, alpha 2 & COLIIA2 & & ? & ? \\
\hline Retinoid $\times$ receptor, beta & $\mathrm{R} X \mathrm{RB}$ & & CK8793II & CK357003 \\
\hline Chitin synthase & & & n.i. & DW550858 \\
\hline Solute carrier family 39 (zinc transporter), member 7 & SLC39A7 & KE4, FABGL & DW552689 & DW563433 \\
\hline Reverse transcriptase & RT & & DW561676 & n.i. \\
\hline Ring finger protein I & RINGI & RNFI & DY732022 & n.i. \\
\hline Ribosomal protein SI8 & RPSI8 & KE3 & DY72936I & n.i. \\
\hline Vacuolar protein sorting 52 & VSP52 & SAC2 & DY740244 & n.i. \\
\hline VHSV induced gene & VHSV & & DW547400 & n.i. \\
\hline
\end{tabular}

Mostly one match is listed per gene. Current abbreviation vs. older nomenclature is listed for each gene. All EST/cDNA sequences are from Genbank (? denotes unidentified EST, n.i. denotes not identified).

verification of expressed $U B A$ alleles in this animal. To verify the linkage between 92I04 and 30C23 fluorescent in situ hybridization was undertaken and showed that both BACs hybridized to the same region of one of the smallest chromosomes, potentially chromosome 27 (Fig. 6 ). The close linkage described by Miller et al. [5] between $U L A$ and UBA also supported 30C23/868001 being an extension of the IA region.

\section{Sasa-ULA}

The ULA locus residing approximately $50 \mathrm{~kb}$ upstream of the UBA locus matched a partial $U L A^{*} 0102$ sequence [Genbank:DQ091800] described by Miller et al. [5]. Another EST in the cGRASP database $[34,35]$ provided us with a full-length match [Genbank:DY699730]. The exon encoding the transmembrane domain is missing, suggestive of a secreted MHC class I molecule (Fig. 4). Similar secretory class I molecules are also found for human class I molecules and the potential role of secretory HLA-G is currently being deciphered and holds promise for an interesting function. The 30C23 ULA gene has an $\alpha 1$ exon with highest sequence identity to $U B A^{*} 0301$ while $\alpha 2$ and downstream exons have highest identity to $U B A^{*} 0801$.
No ESTs for ULA have been identified in rainbow trout, and a negative PCR-based survey for this gene in rainbow trout by Miller et al. [5] suggest this gene may be unique to Atlantic salmon.

\section{Sasa-UCA $\psi$}

Only one MHC class I locus was identified in the four BACs representing the IB region. This locus found in 8I14 showed highest sequence identity to the Onmy UCA*0301 allele and was thus denoted Sasa-UCA. Multiple salmon ESTs with a polymorphic pattern resembling that of Onmy-UCA sequences were found in databases. However, both the 8I14 UCA ORF sequence as well as matching ESTs (Table 1), contained an internal stop codon in exon 3 making Sasa-UCA an expressed pseudogene. The exon intron organization of the UBA, ULA and UCA $\psi$ loci are quite similar apart from the enlarged first intron in ULA, the even larger second intron of $U B A$ and the missing transmembrane exon of ULA (Fig. 7).

\section{Antigen presenting genes}

Previously reported CDNAs for TAP2, which were assumed to reside in the IA and IB region and denoted TAP2B [Gen- 


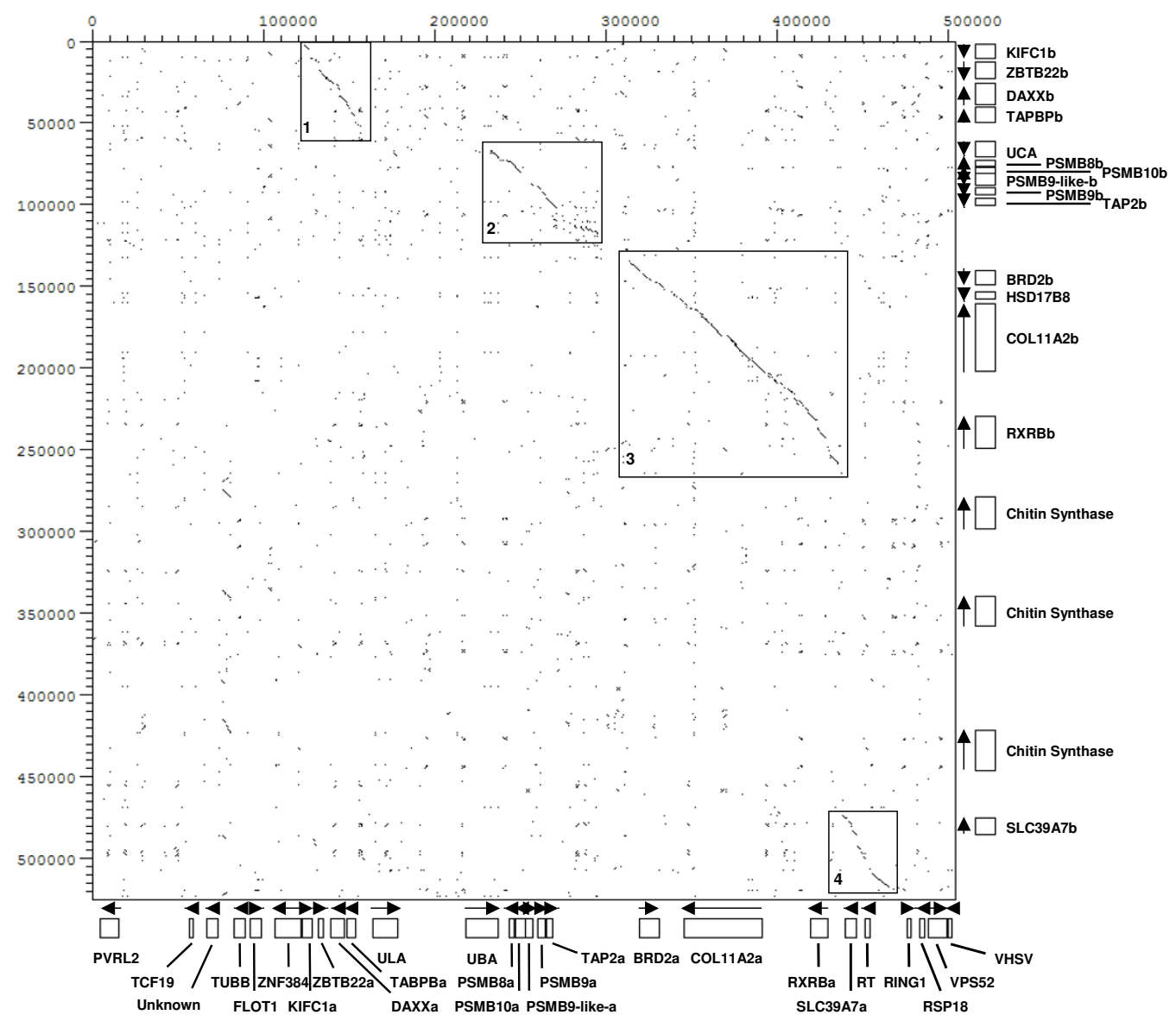

\section{Figure 3}

Dot-plot analysis of the Atlantic salmon MHC IA and IB regions. The IA region is a collection of the BAC clones $30 \mathrm{C} 23,868 \mathrm{O}$ II, 7I 4P22 and 523MI9. The IB region is a summary of the BAC sequences 8II4, 424MI7, I5L20 and I89MI8. Position of genes is shown on the right (IB) and below (IA), and direction of transcription is marked with arrows. Genes found in both regions have an $\mathrm{a}$ or $\mathrm{b}$ extension.

bank:Z83329] and TAP2A [Genbank:Z283328] [36] respectively, indeed did match the TAP2 in the IA and IB BAC sequences. To avoid nomenclature confusion we hereby rename our IA UBA-linked TAP2 locus to TAP2a and the IB UCA $\psi$ linked TAP2 locus to TAP2 $b$. We adapted a similar nomenclature for the reported rainbow trout TAP2 sequences, and suggest that TAP2 sequences without locus identification should be denoted TAP2 only (Fig. 8). Atlantic salmon IA and IB TAP2 sequences have more than $90 \%$ aa sequence identity and a similar identity to the rainbow trout IA and IB TAP2 sequences described by Shiina et al. [6].

Other TAP2 ESTs were also found in databases, which were difficult to define as TAP2 $a$ or TAP2 $b$ variants such as the GraspTAP2-1 in Fig. 8. Attempts to decipher locus origin including rainbow trout information shows that the
TAP2 $a$ and TAP2 $b$ sequences described by Shiina et al. [6] resembles the $T A P 2 b$ sequence identified in Atlantic salmon containing for instance the characteristic FCA motif at position 25 and the two aa deletion at position 110 (Fig. 8). A rainbow trout TAP2a (previously denoted TAP2B) [Genbank:AAD53035] sequence described by Hansen et al. [37], shown by in situ hybridization to reside in the IA region [8], resembles the Atlantic salmon IA TAP2 $a$ sequence and does not contain these motifs mentioned above. Thus, rainbow trout has a polymorphic TAP2 $a$ locus and the confusing sequence identities between the two TAP2 loci may suggest that these genes are exposed to recombination or gene conversion mechanisms. Locus designation of either salmon or trout TAP2 sequences therefore can not be performed on sequence alone, but must be verified by linkage mapping. Other more divergent Atlantic salmon TAP2 ESTs [Gen- 


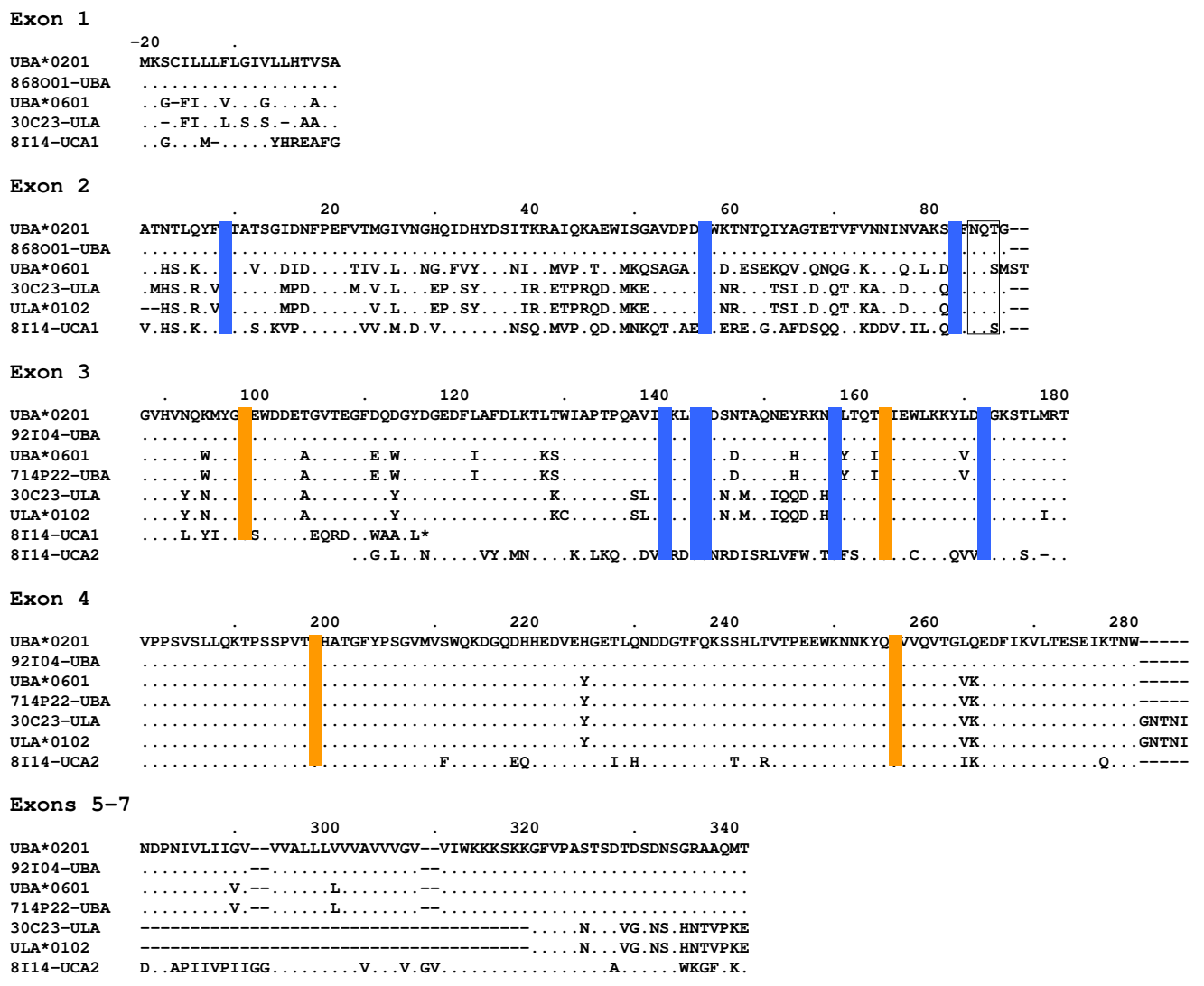

\section{Figure 4}

Alignment of Atlantic salmon UBA, ULA and UCA alleles. Comparison of Atlantic salmon UBA, ULA and the two reading frames of UCA sequences found in the BACs. Also shown is UBA*020I [Genbank:AAN75II7] with exon I sequence from [Genbank:DY698957], UBA*060I [Genbank:AAN75I07] with exon I sequence from [Genbank:DW579225] and ULA*0I02 [Genbank:AAZ73|I5]. Residues critical for binding of peptide anchors are in blue, and disulfide-bridge cysteins are in orange while the glycosylation site is boxed. Dots indicate identity while dashes indicate missing residues.

bank:DW580644 and Genbank:DW577601] have approx. 50\% sequence identity to all above described IA and IB TAP2 sequences (GraspTAP2-2 in Fig. 8), but has $94 \%$ sequence identity to a rainbow trout TAP2 variant described by Hansen et al. [37] (previously denoted TAP2A) [Genbank:AF115537]. If these sequences represent an additional TAP2 locus, i.e. a TAP2c locus, or are allelic variants of the TAP2a/b loci is currently unknown. Ancient lineages of divergent MHC class I, TAP1, TAP2 and LMP7 haplotypes have been described in Xenopus where the sequence identity between allelic TAP2s was less than $76 \%$ [38]. Similar ancient lineages of $U B A$ and TAP2 $a$ may also exist in salmonids, where we were unfortunate enough to sequence allelic variants belonging to similar lineages.
All PSMBs genes in the salmon IA and IB regions were fully intact, as opposed to the IA region in rainbow trout where PSMB8 was a pseudogene, lacking the first three exons. The core region PSMB8, PSMB9, PSMB9-like, $P S M B 10$ and TAP2 loci were found to be organized in a similar fashion in both regions and also displayed a high amount of sequence identity (Table 2). Some nucleotide differences were found between the allelic BACs 92I04 and $714 \mathrm{P} 22$ genes that resulted in amino acid changes; $P_{S M B 10 a^{*} 01}$ and $P S M B 10 a^{*} 02$ had 2 aa differences located in the propeptide at position 12 (T vs. S) and 17 (E vs. K). The proteasome subunits therefore seem to be non-restrictive in providing peptides for UBA molecules as opposed to Xenopus where PSMB8 (LMP7) segregates in lineages with MHC class I, TAP1 and TAP2 [39]. 


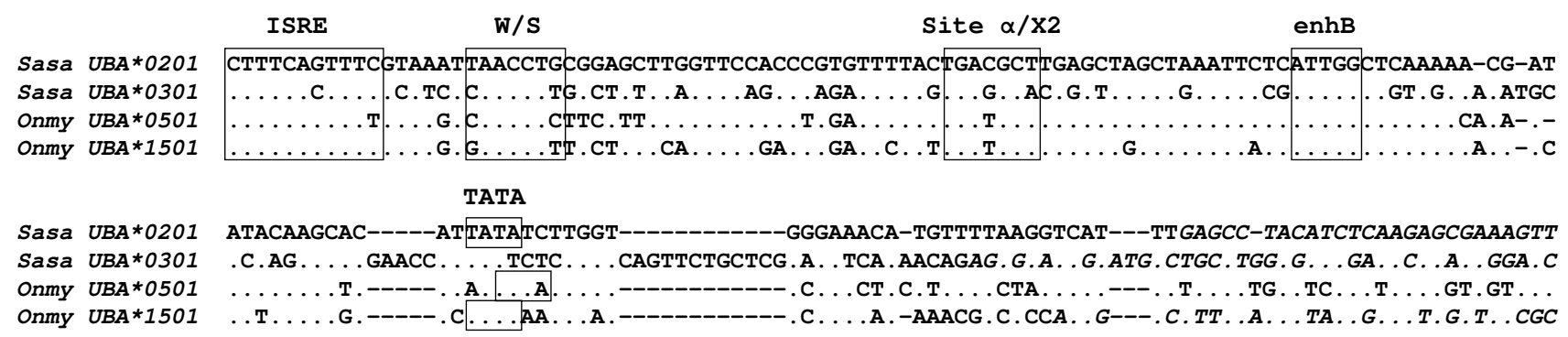

Figure 5

Comparison of UBA promoter elements. Comparison of the SasaUBA*020I promoter region with other reported UBA promoters in Atlantic salmon and rainbow trout; SasaUBA*030I [Genbank:DQ24389I], OnmyUBA*050I [Genbank:ABI62342] and OnmyUBA*I50I [Genbank:AF44I856]. Promoter elements are boxed [3I,32] and the genomic sequences with complete identity to 5'UTRs of UBA cDNA alleles are indicated in italics. Dots indicate identity while dashes indicate gaps.

Tapasin (TAPBP) is a key member of MHC class I antigenloading complexes, linking the class I molecule to the TAP. A full-length cDNA [Genbank:DQ451008] recently described by Jorgensen et al. [40] matched the TAPBPa locus in IA and another EST matched the TAPBPb locus in IB. As opposed to Atlantic salmon, the rainbow trout TAPBP in the IB region was described as a pseudogene both by Shiina et al. [6] as well as by Landis et al. [41] due to a deletion of the last 3 or 4 exons respectively. Landis et al. did however find transcripts of the first 4 exons. Different rainbow trout strains were used in the two studies, potentially accounting for the observed differences in deleted exons.

The core IA region in Atlantic salmon, ranging from the UBA $\alpha 2$ exon and downstream including TAP2, shows $87.6 \%$ sequence identity over 20289 bp to the same region in rainbow trout. A comparison of the salmon and rainbow trout IB region sequences from PSMB8 to TAP2 show $91.4 \%$ identity over 20331 bp. This would be in accordance with the general perception that UBA lineages are ancient while the polymorphism of the duplicated IB region has evolved after the duplication event.

\section{Salmonid MHC evolution and function}

In the Atlantic salmon IB region we found only one $\mathrm{MHC}$ class I pseudo locus denoted UCA $\Psi$, which is still being transcribed and shows a polymorphic pattern similar to that of rainbow trout UCA and UDA [42]. The rainbow trout IB region contained four MHC class I loci denoted UCA, UDA, UEA and UFA $\Psi[6]$. As suggested by Shiina et al. [6] there has been a primordial salmonid MHC region containing three MHC class I loci (UCA-, UEA - and UBAlike) where UEA and UBA have been deleted from the Atlantic salmon IB region and UCA and UEA have been deleted from the Atlantic salmon IA region. The trout IB $U D A$ locus is a duplication of UCA that occured in trout only. Once the extended trout IA region is sequenced we will see if the UBA to ULA duplication occurred in both species and if the UCA and UEA homologues have been retained in this region of trout.

The salmonid whole-genome duplication was estimated to have occurred between 25 and 125 mya [18] while the study of Shiina et al. [6] estimate the duplication to have occurred 60 mya based on sequence identity of the MHC class I regions. Evolving from a tetraploid to a diploid state includes not only accumulation of mutations, but also random rearrangements and recombinations as exemplified by the multiple deletions that have occurred in the Atlantic salmon IA and IB regions. With a sequence identity between the Atlantic salmon IA and IB regions of approximately 82 percent, recombination may even be occurring between the two duplicates today. Salmonids are also known for using recombination within the second intron of the UBA locus to generate "new" alleles using exons already tested for functionality [2-4]. As recombination was not observed in 800 siblings [43] the recombination frequency is probably low. One way of reducing the risk of recombination between duplicates may be insertions such as the $220 \mathrm{~kb}$ insertion with three copies of chitin synthase genes in the IB region.

Another example of differences between Atlantic salmon and rainbow trout is the chromosomal location of the IA region. In both species, the IB region is located on chromosome $14[6,8]$ (data not shown for salmon), while the IA region is located on chromosome 18 in rainbow trout and on one of the smaller chromosomes, potentially chromosome 27, in Atlantic salmon (Fig. 6) $[8,44]$. In Atlantic salmon, the IA and IB regions map to linkage groups 15 and 3 respectively [45], while in rainbow trout they map to linkage groups 16 and 3 [20] supporting the differences. Atlantic salmon and rainbow trout have diploid chromosome numbers ranging from 58 to $64[46,47]$. Most likely, different centric fusions have occurred in the 


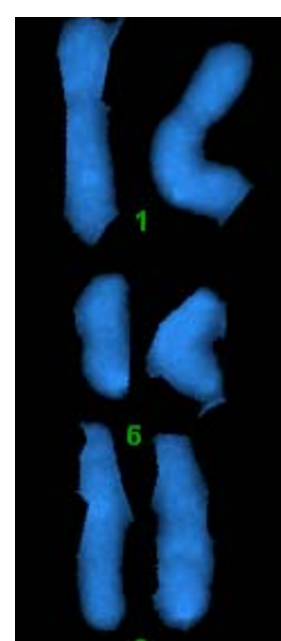

9

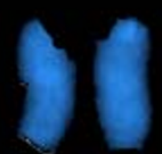

16

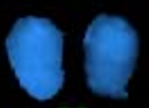

23

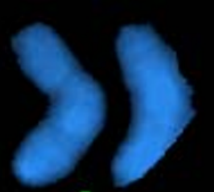

2

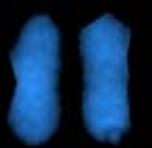

7

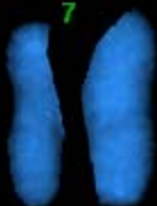

10

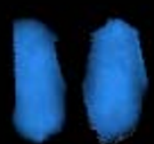

17

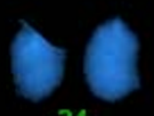

24
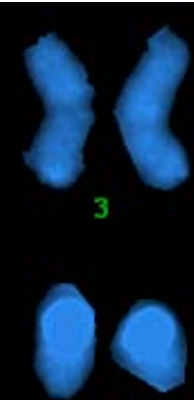

8

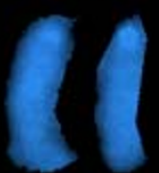

11

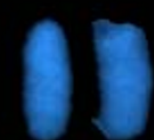

18

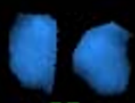

25

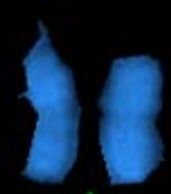

4

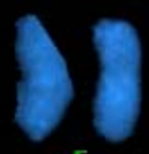

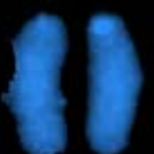

12

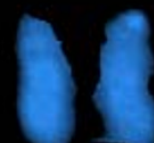

13

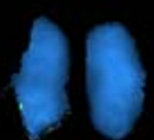

19

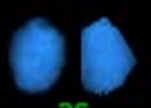

26

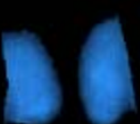

20

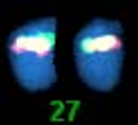

1

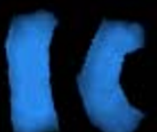

14

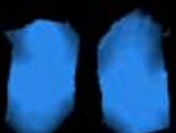

15

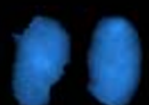

21

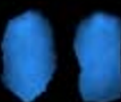

22

Figure 6

FISH mapping of BAC clones. Both 92104 (in red) and 30C23 (in green) hybridized to one of the smallest chromosome, potentially chromosome 27 defining the Atlantic salmon IA region.

diploidization processes of Atlantic salmon and rainbow trout leading to IA residing on one arm of a metacentric chromosome in rainbow trout while on an acrocentric chromosome in Atlantic salmon.
Why the Atlantic salmon IB region has undergone more deletions than trout is unknown, but it has functional consequences. The IB region has been identified as a major QTL for resistance towards IHNV in Atlantic

Table 2: Sequence comparison between antigen presenting genes in the MHC IA and IB regions in Atlantic salmon and rainbow trout

\begin{tabular}{|c|c|c|c|c|c|c|}
\hline GENE & $\%$ nt Sasa IA/IB & $\%$ aa Sasa IA/IB & $\%$ nt IA Sasa/Onmy & $\%$ aa IA Sasa/Onmy & $\%$ nt IB Sasa/Onmy & $\%$ aa IB Sasa/Onmy \\
\hline PSMB8 & 95 & 95 & - & 98 & 96 & 98 \\
\hline PSMBIO & 94 & 92 & 94 & 92 & 97 & 98 \\
\hline PSMB9-like & 96 & 99 & 97 & 97 & 98 & 99 \\
\hline PSMB9 & 97 & 100 & 96 & 98 & 98 & 99 \\
\hline TAP2 & 92 & 90 & 94 & 93 & 96 & 95 \\
\hline
\end{tabular}

The table shows comparison of \% nucleotide $(\mathrm{nt})$ and \% amino acid (aa) identity between the genes found respectively in the Atlantic salmon IA vs $\mathrm{IB}$ region and in the IA and IB region of Atlantic salmon versus rainbow trout [6]. 

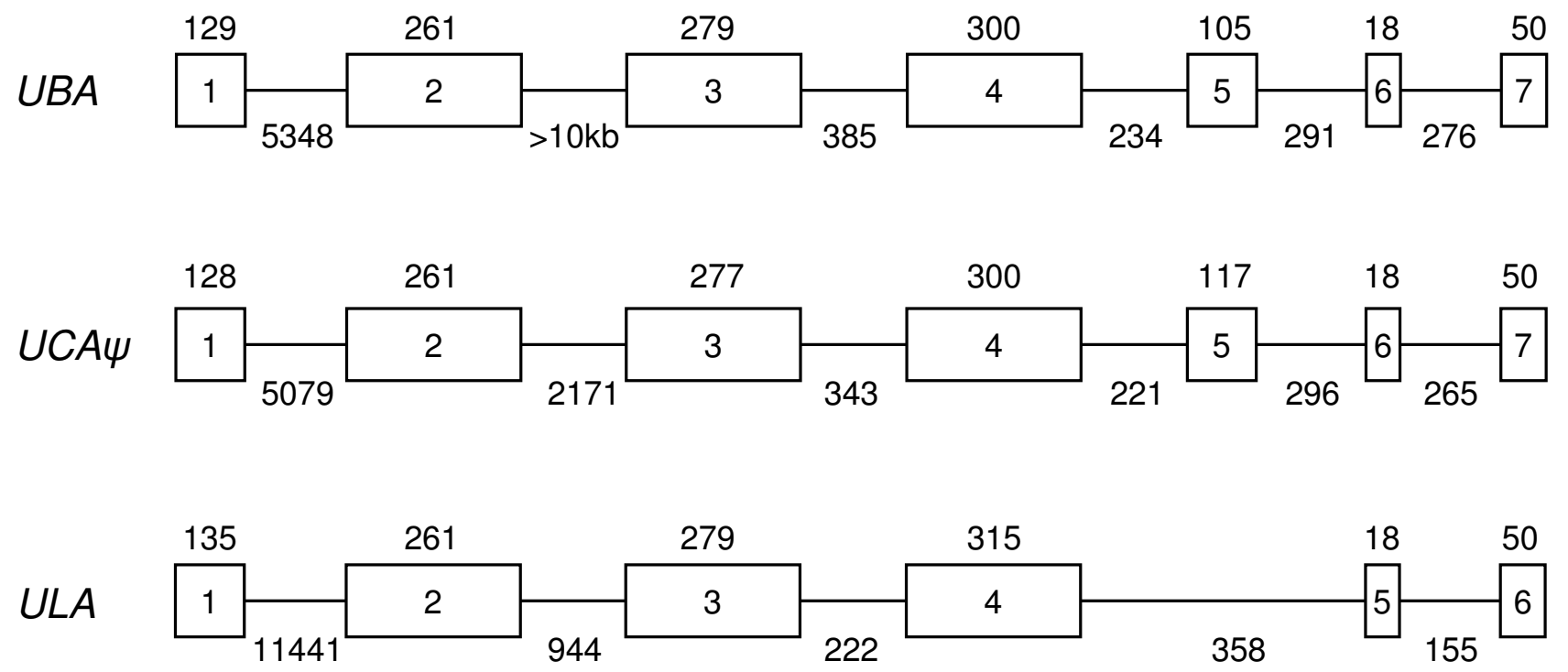

Figure 7

Exon intron organization of the Atlantic salmon UBA, UCA $\psi$ and ULA loci. The exons are boxed with the sizes in bp above sequence and intron sizes below.

salmon and IPNV in rainbow trout where the polymorphic UCA, UDA or UEA loci were suggested as prime candidates for the observed effects $[23,24]$. As our study indicates that the Atlantic salmon IB region only contains a UCA pseudolocus, there must either be other genes flanking our BACs which contribute to resistance or there could be haplotype variation in number of class I loci between Norwegian and Canadian Atlantic salmon.

The IA region was not found associated with resistance towards IHNV in Atlantic salmon nor IPNV in rainbow trout. Atlantic salmon UBA genotypes have however been shown to provide resistance towards the viral pathogen causing Infectious Salmon Anaemia (ISA) [21,22]. An ongoing study will identify the role of Atlantic salmon IA and IB in providing resistance towards IPNV, enabling us to decipher between differences in pathogens versus genetic organization. Apart from the potential TAP2 $a$ and UBA lineages, limited polymorphism in PSMBs and other linked loci suggest that the observed linkage between Sasa-UBA and disease resistance in Norwegian Atlantic salmon $[21,22]$ is caused by Sasa-UBA alleles or genotypes and not closely linked genes. However, the PSMBs and TAP2 molecules residing in the IB region might still influence the overall peptide repertoire available for presentation by $U B A$ alleles. Due to the pseudo status of Sasa-UCA, the PSMBs and TAP2B in the IB region will most likely devolve over time.

\section{Conclusion}

We have characterized the gene organization of more than $500 \mathrm{~kb}$ of the two duplicated MHC regions in Atlantic salmon. Although Atlantic salmon and rainbow trout are closely related, the gene organization of their IB region has undergone extensive gene rearrangements. The Atlantic salmon had only one identified MHC class I UCA pseudo gene in the IB region while this region in trout contained the four MHC class I loci UCA, UDA, UEA and $U F A \psi$. The Atlantic salmon IB region also contained a $220 \mathrm{~kb}$ insertion as compared to the IA region potentially limiting recombination between the two regions. The large difference in gene content and most likely function of salmon and trout class IB regions clearly argues that sequencing of salmon will not necessarily provide information relevant for trout and vice versa.

\section{Methods}

\section{Screening of the BAC library}

An Atlantic salmon BAC library (CHORI214) was obtained from CHORI [48]. The library consisted of approximately 300.000 recombinant clones with an average insert size of $190 \mathrm{~kb}$, representing 18-fold genome coverage [49]. All filters in the library were hybridized with two probes containing conserved exons of the Sasa$U B A$ and Sasa-TAP2 loci or using over go's as described by Han et al. [50]. Both probes were PCR amplified (primers listed in Table 3 ) from cDNA clones and gel purified, and 


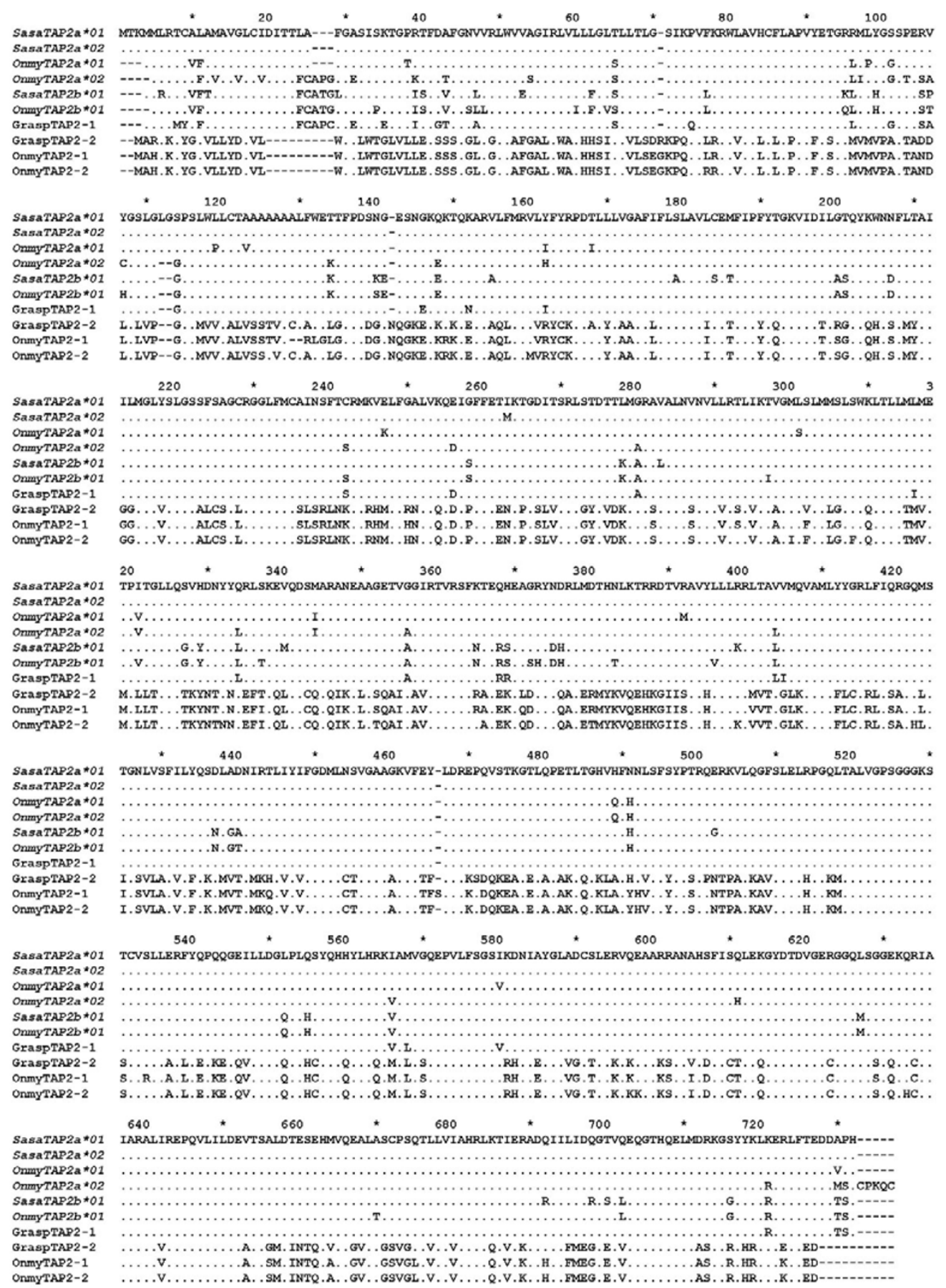

\section{Figure 8}

TAP2 sequence alignment. A comparison of the amino acid sequences for TAP2s in Atlantic salmon and rainbow trout. SasaTAP2a*0I and SasaTAP2a*02 are from the allelic BACs 7I4P22 and 92104 respectively while SasaTAP2b*0I is from the IB region BAC 8II4. GraspTAP2-I represents an assembly of GRASP EST-clones [Genbank:DW55I454, Genbank:DW563627, Genbank:DW563628, Genbank:DW580394 and Genbank:DY730930]), as does GraspTAP2-2 [Genbank:DW54493I, Genbank:DW577600, Genbank:DW57760I, Genbank:DW580644]. The TAP2 sequences from rainbow trout are OnmyTAP2a*01 [Genbank:AAD53035], OnmyTAP2-I [Genbank:AAB62237], OnmyTAP2-2 [Genbank:AAD53034], OnmyTAP2a*02 [Genbank:BAD89546] and OnmyTAP2b*0I [Genbank:BAD89558]. 
Table 3: Primers used for probes, southern hybridization and PCR

\begin{tabular}{|c|c|c|c|}
\hline & Sequence $\left(5^{\prime}-3^{\prime}\right)$ & Position & Comments \\
\hline \multicolumn{4}{|l|}{ UBA $540 \mathrm{~F}$} \\
\hline UBA TmR & TCTTCTTCCAAATGACGACCCC & Exon 5 & cDNA amplification Sasa-UBA \\
\hline TAP2.550F & GCGGGACACCGTCAGGGCAGT & Exon 5 & cDNA amplification Sasa-TAP2a/b \\
\hline TAP2.850R & CGGCCCCACCAGAGCAGTCAG & Exon 8 & cDNA amplification Sasa-TAP2a/b \\
\hline PSMB8.50F & GACTTCGTGGGCAGATTCTT & Exon 2 & cDNA amplification Sasa-PSMB8 \\
\hline PSMB8.350R & TCAGCAGCACTACCAGACAT & Exon 3 & cDNA amplification Sasa-PSMB8 \\
\hline PSMB9b4.590F & GAGGACTGCCAACAGTTTGTT & Exon 4 & cDNA clone (2B4) amplification Sasa-PSMB9 \\
\hline PSMB9b4.876R & ATATCATGCTGGCACAATGTT & 3' UTR & cDNA clone (2B4) amplification Sasa-PSMB9 \\
\hline UBAleadI.F & CTGGGAATAGGCCTTCTACAT & Exon I & Sasa-UBA $* 0201, * 0801, * 0901$ specific \\
\hline UBAlead2.F & AGCCСTACATTCTTCATCTGC & Exon I & Sasa-UBA*0301,*1001 specific \\
\hline UBA02.285R & GTTTGATTGAAGCGGGATTTC & Exon 2 & Sasa-UBA*020I specific \\
\hline UBA03.28IR & TCTGATTGAAGCGCTGCTTGG & Exon 2 & Sasa-UBA*030I specific \\
\hline UBA08.280R & CTGATTGAAGCGCTGCTTGAC & Exon 2 & Sasa-UBA*080I specfic \\
\hline UBA0I.286R & GTTTGATTGAAACGTGTCTG & Exon 2 & Sasa-UBA*090I specific \\
\hline UBA I0.272R & TTGAAAGATTGTGAGGTGCT & Exon 2 & Sasa-UBA*I00I specific \\
\hline ssal.phc-004.039-2 & $\begin{array}{l}\text { CTCTCCAGTGACCTGCCACGCTACAGGTTTCTATCCCAGTGGAGTCATGGTGTTCT } \\
\text { GGCAGAAAGATGGA }\end{array}$ & & MHC Non-classical \\
\hline ssal.rgb-532.282-r & $\begin{array}{l}\text { GCCAATGTGCTCATGGCTATAGTCATCATTGTGTCTGTAGTCTTGATACTCACTGTC } \\
\text { CTATTCAAGTATT }\end{array}$ & & MHC Non-classical \\
\hline ssal.rgb-505.101 & $\begin{array}{l}\text { GCTACCATCGGCTCAAAGAGGAACTCTTTGAGGACTGATTAGGAATCACACAGCTG } \\
\text { TCAGAGAGAGAGAC }\end{array}$ & & TAP2 \\
\hline ssal.rgb-516.329 & $\begin{array}{l}\text { TCAACCTGTACCACATGCAGGAGGACGGCTGGATAAAGGTGTGTAAGGAGGACGT } \\
\text { TTCAGAGCTGATC }\end{array}$ & & PSMB8 \\
\hline ssal.rgb-523.298 & $\begin{array}{l}\text { GTTGATGGACAGGAAGGGGAGCTACTACAAACTAAGAGAGAGACTGTTCACGGAA } \\
\text { GACGACACGTCACAT }\end{array}$ & & TAP2 \\
\hline ssal.rgb-550.202 & $\begin{array}{l}\text { TTCATTGGCTATGAGTCGAGATGGTTCCAGCGGAGGCGTGGCCTACCTTGTCACTA } \\
\text { TTGATGAAAAGGGT }\end{array}$ & & PSMB9 \\
\hline 86800I_FI & GGCTTGCGGAGTAGAACACTTGAAAAAGAA & & GAP-primers \\
\hline 86800I_F2 & GCAACCAATACACTGCAGTATTTCTACACGGCCACTTCTGGTATAGATAAC & & GAP-primers \\
\hline 86800I_F3 & TCAATCAAACTGGAGGTGAGTAGAGACAGA & & GAP-primers \\
\hline 7|4P22_RI & CAGCGGAAACGCAACAAACACAAGAATAACTTACTAACAAATTAGAATCA & & GAP-primers \\
\hline 714P22_R2 & AGCATACAACCATGCCGACAACCATC & & GAP-primers \\
\hline 92104_RI & AACATTTCAAGGTGGTGAAACTATTCACAT & & GAP-primers \\
\hline 92104_R2 & AATTAGTTGTTGTTCACTATGTTAATTAGT & & GAP-primers \\
\hline
\end{tabular}

then radioactively labeled with the Rediprime Random Labelling Kit (Amersham), including spermine precipitation of labeled DNA. Filter hybridizations were performed as described by CHORI. Probed BAC library filters were visualized using a Typhoon Phospho Image Scanner (Amersham).

\section{Characterization of BACs}

MHC class I positive BAC clones were ordered into contigs using restriction fragment analysis together with GRASP HindIII fingerprint information [27]. Southern blot analysis of NotI (NEB) and NruI (NEB) digested BAC DNA was performed to characterize the clones. The digested DNA was electrophoresed for $16 \mathrm{~h}$ and then transferred to Hybond membranes (Amersham). The MHC class I and TAP2 probes described earlier together with probes for PSMB8 and PSMB9 (unpublished data), were used for hybridization to the southern blots. A mixed probe containing $5 U B A$ leader to alpha1 exons amplified from the alleles $U B A{ }^{*} 0201,{ }^{*} 0301,{ }^{*} 0801,{ }^{*} 0901$ and ${ }^{*} 1001$ cDNAs (primers listed in Table 3 ) was also used. Hybridization with end-labeled Sp6 and T7 oligos were used to orient end-fragments of BAC inserts.
Blots were prehybridized at $65^{\circ} \mathrm{C}$ for 30 minutes in hybridization buffer $(5 \times$ SSC, $5 \times$ Denhardt's solution and $1 \%$ SDS) with. This was followed by replacement with fresh, preheated $\left(65^{\circ} \mathrm{C}\right)$ hybridization buffer and the addition of the radio labeled probes. Hybridization was allowed to proceed overnight. Following hybridization, the membranes were washed three times with $20 \mathrm{ml}$ of $2 \times$ SSC, $0.1 \%$ SDS at $65^{\circ} \mathrm{C}$ for $30 \mathrm{~min}$. Prehybridization, hybridization and wash conditions were the same for all probes. To further characterize the BACs we used primers spanning a polymorphic (CA)n repeat located in the 3'UTR of the UBA locus [3] both on individual BAC DNA as well as on genomic DNA from the animal the library was made from. PCR on genomic DNA from the BAC library animal was performed with GAP-primers (Table 3) with Herculase Enhanced polymerase (Stratagene) according to protocol. Amplified products were ligated into the three different vectors using TOPO-TA Cloning Kit with pCR2.1-TOPO (Invitrogen), TOPO-XL PCR Cloning Kit with pCR-XL-TOPO (Invitrogen) and CloneSmart LCKan Blunt Cloning Kit with pSMART LCKan (Lucigen Corporation) and subsequently transformed into XL-10 Gold cells (Stratagene). 


\section{Sequencing strategy}

The selected BACs were subjected to a shotgun sequencing approach. Briefly, BAC DNA was purified by Nucleobond BAC Maxi Kit (BD Biosciences ClonTech). Isolated BAC DNA was nebulized (Invitrogen) (20PSI/15s) and fragments in size range $2-4 \mathrm{~kb}$ were purified from agarose gel and blunt-ended with Mung Bean Nuclease, T4 DNA polymerase and Klenow (NEB). Fragments were ligated into a pUC19 vector (Fermentas) cut with SmaI, and transformed into XL10-Gold (Stratagene). The sequencing templates were prepared by standard alkaline lysis, and sequencing reactions were run on an ABI3100 or ABI3700 DNA sequencer (Applied Biosystems). Bases were called using Phred $[51,52]$. High quality sequencing reads were assembled using Phrap, and viewed and edited using Consed [53]. Autofinish [54] was used for closing gaps by designing gap-closing primers with subsequent direct sequencing on BAC DNA or PCR amplification and PCR product sequencing. The BAC sequences were submitted to Genbank and given the following accession numbers: 8I14 (188042 bp, [Genbank:EF427379]), 15L20 (145959 bp [Genbank:EF427378]), 30C23 (218410 bp, [Genbank:EF427381]), 92I04 (128344 bp, [Genbank:EF427384]), 189M18 (170847 bp, [Genbank:EF427377]), 424M17 (163489 bp, [Genbank:EF427382]), 523M19 (188299 bp [Genbank:EF427383]), 714P22 (244579bp, [Genbank:EF210363]), and 868001 (140046 bp, [Genbank:EF441211]).

\section{Bioinformatics}

DIGIT [55] and GENSCAN [56] were used to predict novel genes and to identify open reading frames. Dotter [57] was used to compare the BAC sequence to itself as well as to other BACs and to identify duplicated regions. Vista was used for sequence comparisons [58]. Blast searches identified possible functions of predicted genes [59]. Sim4 [60] and Spidey [61] were used to adjust exon and intron boundaries aligning EST/CDNA sequences to the BAC sequences. Repeatmasker [62] were used to identify repeats. Multiple sequence alignments of the assumed or verified expressed exons were done using ClustalX [63] followed by manual inspection.

\section{In situ hybridization and karyotyping}

Blood was cultured from the Norwegian strain of Atlantic salmon using standard methods [64]. DNA was isolated from three BAC clones (8I14, 30C23 and 92I04) from the CHORI library using the Qiagen Midi-Preparation kit. These clones were labeled with either Spectrum Orange (Vysis, Inc.) using a nick translation kit (Vysis, Inc.) or digoxigenin according to manufacturers instructions. Human placental DNA $(0.2 \mu \mathrm{g})$ and Cot- 1 DNA $(1 \mu \mathrm{g}$, prepared from Atlantic salmon) were added to the probe mixture for blocking. Hybridizations were carried out at $37^{\circ} \mathrm{C}$ overnight and post-hybridization washes were as recommended by the manufacturer (Vysis, Inc.) with minor modifications [65]. Secondary antibodies to Spectrum Orange (Molecular Probes) were used to amplify the signal in some cases. Slides were counter-stained with 4'6'diamidino-2-phenylindole (DAPI) at a concentration of $125 \mathrm{ng}$ DAPI in $1 \mathrm{ml}$ antifade solution. Images were captured with a Sensys camera and analyzed with Cytovision Genus (Applied Imaging, Inc.) software.

\section{Authors' contributions}

MFL: Performed sequencing, sequence data analysis, annotations and drafted the manuscript.

$\mathrm{HH}$ : Performed library screening, sequencing and BAC restriction mapping.

UG contributed to project design, library screening, sequencing and revision of manuscript.

HGB, MBS, GAC and LR: Performed library screening and sequencing.

RBP: Labelled BAC clones and performed fluorescence in situ hybridization on salmon chromosomes.

KMM: Identified 30C23 containing ULA, performed some sequence annotation

WSD contributed to the project planning and directions.

BFK contributed to the planning, design, direction and analysis.

All authors read and approved the final manuscript.

\section{Acknowledgements}

The present study was supported by The National Programme for Research in Functional Genomics in Norway (FUGE), The Research Council of Norway, and by NSERC, Genome Canada, Genome BC, and the Province of British Columbia.

\section{References}

I. Shiina $T$, Inoko $H$, Kulski JK: An update of the HLA genomic region, locus information and disease associations: 2004 . Tissue Antigens 2004, 64:63 I-649.

2. Aoyagi K, Dijkstra JM, Xia C, Denda I, Ototake M, Hashimoto K, Nakanishi T: Classical MHC class I genes composed of highly divergent sequence lineages share a single locus in rainbow trout (Oncorhynchus mykiss). J Immunol 2002, 168:260-273.

3. Grimholt U, Drablos F, Jorgensen SM, Hoyheim B, Stet RJM: The Major Histocompatibility Class I locus in Atlantic salmon (Salmo salar L.): Polymorphism, linkage analysis and protein modelling. Immunogenetics 2002, 54:570-58I.

4. Shum BP, Guethlein L, Flodin LR, Adkison MA, Hedrick RP, Nehring RB, Stet RJ, Secombes C, Parham P: Modes of salmonid MHC class I and II evolution differ from the primate paradigm. J Immunol 200I, 166:3297-3308.

5. Miller KM, Li S, Ming TJ, Kaukinen KH, Schulze AD: The salmonid MHC class I: more ancient loci uncovered. Immunogenetics 2006, 58:57|-589. 
6. Shiina T, Dijkstra JM, Shimizu S, Watanabe A, Yanagiya K, Kiryu I, Fujiwara A, Nishida-Umehara C, Kaba Y, Hirono I, Yoshiura Y, Aoki T, Inoko H, Kulski JK, Ototake M: Interchromosomal duplication of major histocompatibility complex class I regions in rainbow trout (Oncorhynchus mykiss), a species with a presumably recent tetraploid ancestry. Immunogenetics 2005, 56:878-893.

7. Dijkstra JM, Katagiri T, Hosomichi K, Yanagiya K, Inoko H, Ototake M, Aoki T, Hashimoto K, Shiina T: A third broad lineage of major histocompatibility complex (MHC) class I in teleost fish; MHC class II linkage and processed genes. Immunogenetics 2007, 59:305-321.

8. Phillips RB, Zimmerman A, Noakes MA, Palti Y, Morasch MR, Eiben L, Ristow SS, Thorgaard GH, Hansen JD: Physical and genetic mapping of the rainbow trout major histocompatibility regions: evidence for duplication of the class I region. Immunogenetics 2003, 55:56I-569.

9. Michalova $\mathrm{V}$, Murray BW, Sultmann $\mathrm{H}$, Klein J: A contig map of the Mhc class I genomic region in the zebrafish reveals ancient synteny. I Immunol 2000, 164:5296-5305.

10. Clark MS, Shaw L, Kelly A, Snell P, Elgar G: Characterization of the MHC class I region of the Japanese pufferfish (Fugu rubripes). Immunogenetics 200I, 52:174-185.

II. Matsuo M, Asakawa S, Shimizu N, Kimura H, Nonaka M: Nucleotide sequence of the MHC class I genomic region of a teleost, the medaka (Oryzias latipes). Immunogenetics 2002, 53:930-940.

12. Tsukamoto K, Hayashi S, Matsuo M, Nonaka M, Kondo M, Shima MI, Asakawa S, Shimizu N, Nonaka M: Unprecedented intraspecific diversity of the MHC class I region of a teleost medaka, Oryzias latipes. Immunogenetics 2005, 57:420-43I.

13. Bingulac-Popovic J, Figueroa F, Sato A, Talbot WS, Johnson SL, Gates M, Postlethwait JH, Klein J: Mapping of mhc class I and class II regions to different linkage groups in the zebrafish, Danio rerio. Immunogenetics 1997, 46: I29-134.

14. Naruse K, Fukamachi S, Mitani $H$, Kondo M, Matsuoka T, Kondo S, Hanamura N, Morita Y, Hasegawa K, Nishigaki R, Shimada A, Wada H, Kusakabe T, Suzuki N, Kinoshita M, Kanamori A, Terado T, Kimura $H$, Nonaka $M$, Shima $A$ : A detailed linkage map of medaka, Oryzias latipes: comparative genomics and genome evolution. Genetics 2000, 154:1773-1784.

15. Sambrook JG, Russel R, Umrania Y, Edwards YJK, Campbell RD, Elgar G, Clark MS: Fugu orthologues of human major histocompatibility complex genes: a genome survey. Immunogenetics 2002, 54:367-380

16. Sambrook JG, Figueroa F, Beck S: A genome-wide survey of Major Histocompatibility Complex (MHC) genes and their paralogues in zebrafish. BMC Genomics 2005, 6:152-162.

17. Kasahara M: Genome dynamics of the major histocompatibility complex: insights from genome paralogy. Immunogenetics 1999, 50:134-145.

18. Allendorf FW, Thorgaard GH: Tetraploidy and the evolution of salmonid fishes. In Evolutionary Genetics of Fishes Edited by: Turner BJ. New York, Plenum; 1 984: I-53.

19. Arratia G: Basal teleosts and teleostean phylogeny. Palaeo Ichthyologica 1997, 7:5-168.

20. Phillips RB, Nichols KM, Dekoning J], Morasch MR, Keatley KA, Rexroad C III, Gahr SA, Danzmann RG, Drew RE, Thorgaard GH Assignment of rainbow trout linkage groups to specific chromosomes. Genetics 2006, 174:166I-1670.

21. Kjoglum S, Larsen S, Bakke HG, Grimholt U: How specific MHC class I and class II combinations affect disease resistance against infectious salmon anaemia in Atlantic salmon (Salmo salar). Fish Shellfish Immunol 2006, 2 I:43 I-44I.

22. Grimholt U, Larsen S, Nordmo R, Midtlyng P, Kjoeglum S, Storset A, Saebo $S$, Stet RJ: MHC polymorphism and disease resistance in Atlantic salmon (Salmo salar); facing pathogens with single expressed major histocompatibility class I and class II loci. Immunogenetics 2003, 55:210-219.

23. Miller KM, Winton JR, Schulze AD, Purcell MK, Ming TJ: Major histocompatibility complex loci are associated with susceptibility of Atlantic salmon to infectious hematopoietic necrosis virus. Environ Biol Fishes 2004, 69:307-316.

24. Ozaki A, Sakamoto T, Khoo S, Nakamura K, Coimbra MR, Akutsu T, Okamoto N: Quantitative trait loci (QTLs) associated with resistance/susceptibility to infectious pancreatic necrosis virus (IPNV) in rainbow trout (Oncorhynchus mykiss). Mol Genet Genomics 200I, 265:23-3I.
25. McKay SJ, Devlin RH, Smith MJ: Phylogeny of Pacific salmon and trout based on growth hormone type-2 and mitocondrial NADH dehydrogenase subunit 3 DNA sequences. Can J Fish Aquatic Sci 1996, 53: I 165-1168.

26. Kibenge FS, Kibenge MJ, Groman D, McGeachy S: In vivo correlates of infectious salmon anemia virus pathogenesis in fish. J Gen Virol 2006, 87:2645-2652

27. Ng SH, Artieri CG, Bosdet IE, Chiu R, Danzmann RG, Davidson WS, Ferguson MM, Fjell CD, Hoyheim B, Jones SJ, de Jong PJ, Koop BF, Krzywinski MI, Lubieniecki K, Marra MA, Mitchell LA, Mathewson C, Osoegawa K, Parisotto SE, Phillips RB, Rise ML, von Schalburg KR, Schein JE, Shin H, Siddiqui A, Thorsen J, Wye N, Yang G, Zhu B: A physical map of the genome of Atlantic salmon, Salmo salar. Genomics 2005, 86:396-404.

28. HUGO Gene Nomenclature Committee Internet 2007 [http:// www.genenames.org]

29. Dijkstra JM, Yoshiura Y, Kiryu I, Aoyagi K, Kollner B, Fischer U, Nakanishi T, Ototake M: The promoter of the classical MHC class I locus in rainbow trout (Oncorhynchus mykiss). Fish \& Shellfish Immunology 2003, I4:177-185.

30. Gobin SJ, Peijnenburg A, Keijsers V, van den Elsen PJ: Site alpha is crucial for two routes of IFN gamma-induced MHC class I transactivation: the ISRE-mediated route and a novel pathway involving CIITA. Immunity 1997, 6:60I-6II.

31. van den Elsen PJ, Peijnenburg A, Van Eggermond MC, Gobin SJ: Shared regulatory elements in the promoters of MHC class I and class II genes. Immunol Today 1998, 19:308-3I2.

32. Patikoglou GA, Kim JL, Sun L, Yang SH, Kodadek T, Burley SK: TATA element recognition by the TATA box-binding protein has been conserved throughout evolution. Genes Dev 1999, 13:3217-3230.

33. Jorgensen SM, Lyng-Syvertsen B, Lukacs M, Grimholt U, Gjoen T: Expression of MHC class I pathway genes in response to infectious salmon anaemia virus in Atlantic salmon (Salmo salar L.) cells. Fish Shellfish Immunol 2006, 2 1:548-560.

34. Consortium for Genomics Research on All Salmon Internet 2007 [http://web.uvic.ca/cbr/grasp/].

35. Rise ML, von Schalburg KR, Brown GD, Mawer MA, Devlin RH, Kuipers N, Busby M, Beetz-Sargent M, Alberto R, Gibbs AR, Hunt $P$, Shukin R, Zeznik JA, Nelson C, Jones SR, Smailus DE, Jones SJ, Schein JE, Marra MA, Butterfield YS, Stott JM, Ng SH, Davidson WS, Koop BF: Development and application of a salmonid EST database and cDNA microarray: data mining and interspecific hybridization characteristics. Genome Res 2004, 14:478-490.

36. Grimholt U: Transport-associated proteins in Atlantic salmon (Salmo salar). Immunogenetics 1997, 46:213-22I.

37. Hansen JD, Strassburger P, Thorgaard GH, Young WP, Du PL: Expression, linkage, and polymorphism of MHC-related genes in rainbow trout, Oncorhynchus mykiss. J Immunol I999, 163:774-786.

38. Ohta Y, Powis SJ, Lohr RL, Nonaka M, Pasquier LD, Flajnik MF: Two highly divergent ancient allelic lineages of the transporter associated with antigen processing (TAP) gene in Xenopus: further evidence for co-evolution among MHC class I region genes. Eur J Immunol 2003, 33:3017-3027.

39. Ohta $Y$, Haliniewski DE, Hansen J, Flajnik MF: Isolation of transporter associated with antigen processing genes, TAPI and TAP2, from the horned shark Heterodontus francisci. Immunogenetics 1999, 49:981-986.

40. Jorgensen SM, Grimholt U, Gjoen T: Cloning and expression analysis of an Atlantic salmon (Salmo salar L.) tapasin gene. Dev Comp Immunol 2007, 31:708-7। 9.

4I. Landis ED, Palti Y, Dekoning J, Drew R, Phillips RB, Hansen JD: Identification and regulatory analysis of rainbow trout tapasin and tapasin-related genes. Immunogenetics 2006, 58:56-69.

42. Dijkstra JM, Kiryu I, Yoshiura Y, Kumanovics A, Kohara M, Hayashi N, Ototake M: Polymorphism of two very similar MHC class Ib loci in rainbow trout (Oncorhynchus mykiss). Immunogenetics 2006, 58: 152-167

43. Kiryu I, Dijkstra JM, Sarder RI, Fujiwara A, Yoshiura Y, Ototake M: New MHC class la domain lineages in rainbow trout (Oncorhynchus mykiss) which are shared with other fish species. Fish \& Shellfish Immunology 2005:243-254.

44. Fujiwara A, Kiryu I, Dijkstra JM, Yoshiura Y, Nishida-Umehara C, Ototake M: Chromosome mapping of MHC class I in rainbow 
trout (Oncorhynchus mykiss). Fish \& Shellfish Immunology 2003, 14:17|-175.

45. Salmon Genome Project Internet 2007 [http://www.salmonge nome.no/cgi-bin/sgp.cgi]

46. Phillips R, Rab P: Chromosome evolution in the Salmonidae (Pisces): an update. Biol Rev Camb Philos Soc 200I, 76: I-25.

47. Hartley SE: The chromosomes of salmonid fishes. Biol Rev Camb Philos Soc 1987, 62:197-214.

48. Children's Hospital Oakland Research Institute (CHORI) Internet 2007 [http://bacpac.chori.org/].

49. Thorsen J, Zhu B, Frengen E, Osoegawa K, de Jong PJ, Koop BF, Davidson WS, Hoyheim B: A highly redundant BAC library of Atlantic salmon (Salmo salar): an important tool for salmon projects. BMC Genomics 2005, 6:50-60.

50. Han CS, Sutherland RD, Jewett PB, Campbell ML, Meincke LJ, Tesmer JG, Mundt MO, Fawcett JJ, Kim UJ, Deaven LL, Doggett NA: Construction of a BAC contig map of chromosome 16q by twodimensional overgo hybridization. Genome Res 2000, 10:7|4-72|.

51. Ewing B, Hillier L, WendI MC, Green P: Base-calling of automated sequencer traces using phred. I. Accuracy assessment. Genome Res 1998, 8: 175-185.

52. Ewing B, Green P: Base-calling of automated sequencer traces using phred. II. Error probabilities. Genome Res 1998, 8:186-194.

53. Gordon D, Abajian C, Green P: Consed: a graphical tool for sequence finishing. Genome Res 1998, 8:195-202.

54. Gordon D, Desmarais C, Green P: Automated finishing with autofinish. Genome Res 200I, I I:6/4-625.

55. Digit Web Server Internet 2007 [http://digit.gsc.riken.go.jp/].

56. Burge C, Karlin S: Prediction of complete gene structures in human genomic DNA. J Mol Biol 1997, 268:78-94.

57. Sonnhammer EL, Durbin R: A dot-matrix program with dynamic threshold control suited for genomic DNA and protein sequence analysis. Gene 1995, 167:GCI-10.

58. Frazer KA, Pachter L, Poliakov A, Rubin EM, Dubchak I: VISTA: computational tools for comparative genomics. Nucleic Acids Res 2004, 32:W273-W279.

59. Altschul SF, Gish W, Miller W, Myers EW, Lipman DJ: Basic local alignment search tool. J Mol Biol 1990, 21 5:403-4I0.

60. Florea L, Hartzell G, Zhang Z, Rubin GM, Miller W: A computer program for aligning a cDNA sequence with a genomic DNA sequence. Genome Res 1998, 8:967-974.

61. Wheelan SJ, Church DM, Ostell JM: Spidey: a tool for mRNA-togenomic alignments. Genome Res 200I, I I: 1952-1957.

62. Repeatmasker Internet 2007 [http://www.repeatmasker.org/].

63. Thomson JD, Higgins DG, Gibson TJ: ClustalW: improving the sensitivity of progressive multiple sequence alignments through sequence weighting, position-specific gap penalties and weight matrix choice. Nucleic Acids Res 1994, 22:4673-4680.

64. Reed KM, Phillips RB: Molecular cytogenetic analysis of the double-CMA3 chromosome of lake trout, Salvelinus namaycush. Cytogenet Cell Genet 1995, 70: I04-107.

65. Phillips RB, Reed KM: Localization of repetitive DNAs to zebrafish (Danio rerio) chromosomes by fluorescence in situ hybridization (FISH). Chromosome Res 2000, 8:27-35.
Publish with Bio Med Central and every scientist can read your work free of charge

"BioMed Central will be the most significant development for disseminating the results of biomedical research in our lifetime. "

Sir Paul Nurse, Cancer Research UK

Your research papers will be:

- available free of charge to the entire biomedical community

- peer reviewed and published immediately upon acceptance

- cited in PubMed and archived on PubMed Central

- yours - you keep the copyright
BioMedcentral 